\title{
Paracoccidioidomicose e câncer
}

\section{Paracoccidioidomycosis and cancer}

\section{Ao Editor:}

Li a recente publicação a respeito de paracoccidioidomicose e câncer com grande interesse. Rodrigues et al. concluíram que um diagnóstico de paracoccidioidomicose aumenta o risco para câncer de pulmão. ${ }^{(1)}$ De fato, há relatos sobre esse problema. Aceita-se que a paracoccidioidomicose possa ser uma coinfecção importante em pacientes com câncer. ${ }^{(2)}$ Entretanto, tenho alguns comentários a respeito do artigo de Rodrigues et al. Em primeiro lugar, não deveria haver conclusões a respeito do "risco" no estudo, visto que esse não é um estudo analítico e nem tem um formato de caso-controle. Em segundo lugar, uma revisão retrospectiva de prontuários implica em uma grande possibilidade de subdiagnóstico.

\author{
Viroj Wiwanitkit \\ Professor de Medicina Tropical, \\ Professor Visitante, Hainan Medical \\ College, Haikou, China
}

\section{Referências}

1. Rodrigues Gda S, Severo CB, Oliveira Fde M, Moreira Jda S, Prolla JC, Severo LC. Association between paracoccidioidomycosis and cancer. J Bras Pneumol. 2010;36(3):356-62.

2. Shikanai-Yasuda MA, Conceição YM, Kono A, Rivitti E, Campos AF, Campos SV. Neoplasia and paracoccidioidomycosis. Mycopathologia. 2008;165(45):303-12. 